\title{
Nicotine and Opioids: a Call for Co-treatment as the Standard of Care
}

\author{
Chad D. Morris, PhD \\ Christine E. Garver-Apgar, PhD
}

\begin{abstract}
The U.S. is in the midst of an opioid epidemic. At the same time, tobacco use remains the leading cause of preventable death and disability. While the shared biological underpinnings of nicotine and opioid addiction are well established, clinical implications for co-treatment of these two substance use disorders has not been emphasized in the literature, nor have researchers, clinicians, and policy makers adequately outlined pathways for incorporating co-treatment into existing clinical workflows. The current brief review characterizes the metabolic and neural mechanisms which mediate co-use of nicotine and opioids, and then outlines clinical and policy implications for concurrently addressing these two deadly epidemics. Screening, assessment, medication-assisted treatment (MAT), and tobacco-free policy are discussed. The evidence suggests that clinical care and policies that facilitate co-treatment are an expedient means of delivering healthcare to individuals that result in better health for the population while also meeting patients' substance abuse disorder recovery goals.
\end{abstract}

\section{Introduction}

Healthcare providers have a critical opportunity to concurrently address tobacco and opioid dependence. The policy spotlight on the U.S. opioid epidemic and the dramatic increase in overdose deaths presents an opportunity to bring renewed focus on strategies that potentiate addiction treatment, including nicotine addiction treatment. Over-prescription of opioid pain relievers beginning in the 1990s led to a rapid escalation of dependence, a resurgence of heroin use, and arrival of powerful synthetic opioids such as fentanyl which increased $45 \%$ from 2016 to 2017. ${ }^{1,2}$ In 2017, there were 70,237 drug overdose deaths in the U.S., ${ }^{1}$ and heroin overdoses more than tripled from 2010 to $2014 .^{3}$ In the face of these dire statistics, smoking is often seen as less harmful and a lower treatment priority than opioids which represent a clear, imminent risk. ${ }^{4}$ Yet,

Address correspondence to Chad D. Morris, PhD, University of Colorado, Anschutz Medical Campus, 1784 Racine Street, Campus Box F478, Building 401, Aurora, CO 80045, USA. Email: chad.morris@cuanschutz.edu.

Christine E. Garver-Apgar, PhD, University of Colorado, Anschutz Medical Campus, Aurora, CO, USA.

Journal of Behavioral Health Services \& Research, 2020. 601-613. (C) 2020 National Council for Behavioral Health. DOI 10.1007/s11414-020-09712-6 
smoking combustible tobacco products, not opioid use, remains the leading cause of death and disability in the U.S., with at least 480,000 dying annually due to smoking-related causes. ${ }^{5}$

The general prevalence of current cigarette smoking among U.S. adults is $14 \%$ (16\% for men and $12 \%$ for women). ${ }^{6}$ Smoking is highest among those aged 18-44 (15\%) and 45-64 (17\%). Hispanic adults $(10 \%)$ are less likely to be current smokers compared with non-Hispanic black $(15 \%)$ and non-Hispanic white adults $(16 \%){ }^{6}$ In comparison, smoking prevalence among patients using illicit opioids or who are receiving methadone maintenance treatment is between 74 and $97 \% .^{7-11}$ This is an extremely high rate of co-use even when compared to co-use with other illicit drugs or alcohol. ${ }^{12}$ For instance, $97 \%$ of heroin users in one study of methadone or buprenorphine treatment used an average of 20 cigarettes or a pack per day. ${ }^{13}$ Co-occurring tobacco and opioid use creates an additive effect of increasing toxicity and related health consequences across all body systems, ${ }^{14}$ leading these users to face unnecessarily high mortality and morbidity. ${ }^{15,16}$

While the shared biological underpinnings of nicotine and opioid addiction are well-established, clinical and policy implications have garnered limited attention. Smoking is a primary risk factor for opioid addiction, and there is ample evidence that co-treatment of tobacco and opioid use leads to better outcomes among those seeking treatment for drug use generally and opioid addiction specifically. This article summarizes the neurobiological and clinical evidence suggesting that there is a clinical and ethical imperative to promote co-treatment models as a necessary standard of care.

\section{Biological underpinnings}

Using both opioids and tobacco may enhance subjective positive effects and satisfaction with drug use, reduce withdrawal symptoms for both substances, and act as a substitution when one drug is unavailable. ${ }^{17,18}$ Co-use leads to the increased use of one or both substances through priming, extending reinforcement, and cross-tolerance, thus making abstinence from either substance more difficult. ${ }^{14,19,20}$ In part, cross-tolerance occurs because combustible tobacco use produces polycyclic aromatic hydrocarbons which induce faster metabolism of opioids through induction of hepatic cytochrome P-450 1A2-isoenzymes. ${ }^{21}$ While infrequent, this effect can lead to opioid toxicity when patients quit smoking. ${ }^{22}$ There is also evidence that past smokers using nicotine replacement therapy (NRT) use opioids at the same level as current smokers. As NRT does not produce polycyclic aromatic hydrocarbons, this indicates additional biological mechanisms of cross-tolerance. These bidirectional priming and tolerance between nicotine and opioids include illicit drugs as well as prescribed use of methadone and buprenorphine. ${ }^{23,24}$ In addition to cross tolerance, polysubstance use heightens reinforcement because opioids and tobacco similarly stimulate reward pathways including the dopaminergic, cannabinoid, and nicotinic-acetylcholine (nAChR) systems. ${ }^{25,26}$ As a result of these related metabolic and neural processes, smoking increases opioid use, including opioid replacement medication use. ${ }^{27}$ At the same time, opioid use including prescription replacement drugs reinforces smoking patterns. ${ }^{28,29}$

Chronic pain is also implicated in co-use of tobacco and opioids. Current smoking among persons suffering chronic pain ranges from 24 to $82 \%,{ }^{30,31}$ and findings suggest that there are no significant associations between smoking status and ethnicity, sex, or age. ${ }^{31}$ Paradoxically, acute nicotine use is known to have short-term analgesic effects, but ongoing use leads to chronic pain. Nicotine initially releases endogenous opioids ${ }^{32-34}$ and potentiates opioid-induced antinociception and activates the pain inhibitory pathways in the spinal cord. ${ }^{34-36}$ Chronic nicotine exposure leads to tolerance to this analgesic effect. Indeed, ongoing smoking becomes a risk factor for the onset or exacerbation of back pain, sciatica, arthritis, fibromyalgia, and chronic headache. ${ }^{37-41}$ Nicotine (or perhaps another component in tobacco smoke) may sensitize pain receptors, decrease pain tolerance, and increase pain awareness. ${ }^{42}$ Prospective cohort studies of adolescents bear this out, demonstrating that smoking early in life causes chronic back pain leading to related hospitalizations, initial opioid use, and potential opioid addiction persisting into adulthood. ${ }^{43-45}$ 
Logically, it would follow that smoking cessation might then be a treatment for chronic pain, ${ }^{34,46}$ but randomized controlled trials have not substantiated this hypothesis. ${ }^{41}$ Continued research is needed to further elucidate the complex relationship between smoking and pain.

Regardless of causality, smokers are at increased risk for chronic pain of higher intensity, increased number of painful sites, and more associated disability and adverse effects on occupational and social functioning. ${ }^{33,34,47-49}$ Smokers have higher pain scores and higher need for opioids during surgery and postoperatively compared to nonsmokers. ${ }^{50}$ And studies have found that, in comparison to non-smokers, smokers are more likely to be on opioid pain treatment for longer durations and at higher dosages. ${ }^{51}$ Higher levels of reported pain among smokers may also be related to elevated levels of depression, ${ }^{52}$ and in turn, anxiety and depression heighten the motivation to smoke and increase severity of nicotine withdrawal and pain sensitivity. ${ }^{53}$ Therefore, there is some evidence that treating psychiatric symptoms will lead to improvements in pain symptoms ${ }^{52}$ which may then potentiate reductions in polysubstance use.

\section{Co-treatment}

There is mounting evidence that addressing smoking and other drug use concurrently leads to improved psychiatric and polysubstance use outcomes. ${ }^{54-59}$ At minimum, research has found that smoking cessation while in treatment has no effect on other drug use outcomes. ${ }^{56,57}$ Encouragingly, meta-analysis of 19 randomized controlled trials of smoking cessation interventions found that individuals who treat their addiction to tobacco and other substances simultaneously are $25 \%$ more likely to sustain their recovery, compared to individuals who do not address tobacco while in treatment from other drugs. ${ }^{58}$ As an extension of this meta-analysis, McKelvey and colleagues ${ }^{59}$ synthesized the evidence across 24 studies to show the positive impact of smoking cessation on substance use disorder (SUD) outcomes. Both quitting smoking and smoking cessation treatment interventions had either a positive impact or no impact on substance use outcomes. Positive SUD impacts included reduced drug use and continued abstinence. ${ }^{59}$

In contrast to many healthcare providers' beliefs, patients in treatment for opioids desire assistance with smoking cessation, ${ }^{60}$ with $44 \%$ to $80 \%$ of methadone maintenance clients wanting to quit smoking. ${ }^{61,62}$ The longer patients receive methadone maintenance therapy, the more motivated they become to quit smoking. ${ }^{18,63-65}$ Due to SUD patients' overlapping genetic, neurobiological, and environmental characteristics, similar population level, behavioral, medication, and social service interventions are effective across substance use disorders. ${ }^{2}$ But despite the clear benefits of co-treatment and the fact that patients desire to quit smoking, tobacco cessation services remain infrequently offered in SUD treatment settings. ${ }^{66,67}$ Less than half of SUD treatment centers $(29-42 \%)$ offer tobacco cessation services. ${ }^{68,69}$ Generally, there are an insufficient number of addiction specialists, ${ }^{70}$ and among addiction medicine professionals, the majority receive little training regarding integration of tobacco cessation screening, assessment, referral, and treatment into daily practice.

There are a number of oft cited barriers to addressing smoking in treatment settings including concerns that ${ }^{1}$ agency census levels and completion rates will drop, ${ }^{2}$ tobacco users will be less likely to seek addiction treatment, ${ }^{3}$ patients are neither interested in tobacco cessation nor able to successfully quit tobacco, ${ }^{4}$ patients will relapse to alcohol or drug use if they attempted to quit tobacco, ${ }^{5}$ tobacco-free policies will be difficult to enforce, ${ }^{6}$ clinicians lack the skills to effectively treat tobacco dependence, and ${ }^{7}$ clinicians have too many competing demands preventing attention to smoking cessation. ${ }^{8,71-73}$ Also, few treatment agencies have a designated leader or formalized procedures related to smoking cessation services, the ability to prescribe smoking cessation pharmacotherapies, or an existing budget for cessation interventions. ${ }^{74}$

Historically, many addiction treatment facilities have not only allowed but actively reinforced smoking. ${ }^{75}$ Healthcare providers continue to widely hold the perspective that smoking cannot be 
treated concurrently with other substance use. ${ }^{72}$ In many cases, smoking is directly or indirectly condoned in treatment settings, with a large proportion of SUD treatment providers smoking themselves and smoking with patients while in treatment. ${ }^{76,77}$ Indeed, many patients with SUD report that they first began smoking in addictions or other psychiatric treatment environments. ${ }^{78}$ Additionally, compared to treatment settings where smoking is not allowed, continued smoking in treatment settings is associated with increased opioid withdrawal and cravings, more cigarette use at follow-up, and lower detox completion. ${ }^{60,79-81}$

Organizational affiliation has also played a role in smoking cessation efforts in SUD and other healthcare settings. Over the last decade, cessation services in federally qualified healthcare centers (FQHCs) have been reinforced by Health Resources \& Services Administration (HRSA) tobacco use measures, the ability to bill under the Centers for Medicare and Medicaid Services (CMS), and the Patient Protection and Affordable Care Act. ${ }^{82}$ In the behavioral health sector, early state intiatives mandating tobacco policy and cessation services for substance disorder treatment facilities ${ }^{75,83}$ have been reinvigorated on a national level through the efforts of such organizations as the National Association of State Mental Health Program Directors (NASMHPD), federal Substance Abuse and Mental Health Services Administration (SAMHSA), Smoking Cessation Leadership Center (SCLC), and National Council for Behavioral Health (National Council). ${ }^{84}$ While the cultural shift has been slow, co-treatment of opioids and nicotine addiction among statefunded SUD treatment agencies and opioid treatment centers continues to gather momentum.

Tobacco-Free Policy Facilitators for adequately addressing both tobacco and opioid use include having a lower number of clinicians who smoke, patient incentives, senior leadership support, and ongoing staff training in evidence-based treatment strategies. ${ }^{85,86}$ Tobacco-free policies also heighten clinical effectiveness. Ample evidence suggests that tobacco-free campus policies support co-treatment and should be implemented by treatment agencies. ${ }^{76,87}$ When treatment agencies implement comprehensive tobacco-free policies that include the facility grounds, patients' attitudes about quitting are improved, they receive more tobacco cessation services, and the intent to quit smoking increases. ${ }^{76}$ Tobacco policies not only support quit attempts, but also prevent the initiation of smoking which is associated with higher odds of drug use relapse. Policies can be created by individual agencies or mandated statewide. New York has, among other states, instituted statewide policies among funded SUD treatment agencies. ${ }^{83,88}$ Within inpatient treatment settings, neither forced quit attempts, i.e., smoke-free policies, nor smoking cessation treatment interventions negatively affect other drug use treatment outcomes. ${ }^{59}$ Furthermore, studies show no evidence that smoke-free policies instituted in inpatient treatment settings adversely impact patient census rates. $^{78}$

Screening, Brief Interventions, and Referral A systematic screening, treatment, and referral structure is necessary to adequately address drug use. In behavioral health treatment settings, screening, brief intervention, and referral to treatment (i.e., SBIRT) were originally developed to detect risky substance use and direct providers to intervene early using motivational enhancement strategies. ${ }^{89-91}$ While SBIRT has been demonstrated to be effective for risky alcohol use, there is growing yet varied evidence of effectiveness for other drug use. ${ }^{92-94}$ Recently, Bernstein and D'Onofrio $^{90}$ made modifications to SBIRT, creating a model referred to as STIR (screening, treatment initiation, and referral). The primary difference between SBIRT and STIR is that STIR prompts clinicians to initiate pharmacotherapy for illicit opioid or tobacco use during the initial visit. Recent studies of STIR in emergency departments have demonstrated increased patient engagement and decrease in both tobacco and opioid use. ${ }^{90}$ The equivalent of SBIRT in tobacco control environments is referred to as the " $5 \mathrm{As}$ " (Ask about tobacco use, Advise to quit through 
clear personalized messages, Assess willingness to quit, Assist to quit, and Arrange follow-up and support). ${ }^{95,96}$ Implementation of the 5As in heterogeneous healthcare settings has been an impetus for greater attention to tobacco use, with brief advice from physicians and other clinicians associated with patients' successful quit attempts. ${ }^{97,98}$

Utilizing the SBIRT, STIR or the 5As model, healthcare providers in SUD or primary care settings are much more likely to screen for tobacco use, assess, and advise abstinence, but unfortunately are less likely to follow these actions by providing brief treatment, medicationassisted treatment (MAT), or appropriate referral. ${ }^{99-101}$ This is a substantial practice gap that has been difficult to narrow. ${ }^{102,103}$ The infrequency of appropriate referrals and evidence-based treatments point to the necessity of interdisciplinary healthcare teams as physicians are less responsive than other providers (e.g., nurse practitioners and physicians' assistants) to systemic efforts to increase tobacco cessation treatment. Additionally, regardless of the screening and brief intervention model employed, establishing a SUD patient registry, which includes both opioids and nicotine use, within a practice-based research and/or health care network allows for better data aggregation, patient identification, and stratification to appropriate treatment levels. ${ }^{104}$

Medication-Assisted Treatment Appropriate treatment across substance use disorders typically involves MAT, consisting of a combination of behavioral interventions and medications. ${ }^{105}$ The synergistic effects of MAT apply as equally to smoking cessation as it does to opioid maintenance treatment. Research shows that both tobacco and opioid use treatment should include FDAapproved medications to treat dependence and maximize healthcare utilization. ${ }^{106}$ For opioid dependence, methadone and buprenorphine are approved, as well as naloxone for overdose. For tobacco cessation, a combination of behavioral strategies and seven FDA-approved medications are the most effective means of quitting smoking. ${ }^{95}$

Medications plus behavioral counseling lead to tobacco cessation rates of 25-30\% compared to unaided quit attempts with a success rate of $4-7 \% .{ }^{95}$ For the general population, all FDA-approved cessation pharmacotherapy improves the chances of smoking cessation at 6-month follow-up or longer, compared to placebo. A review of reviews found that NRT and bupropion increase the likelihood that a person will be abstinent from tobacco at 6 months post-quit by about $60 \%$, while varenicline more than doubles the likelihood of abstinence at 6 months compared to a placebo. ${ }^{107}$ The EAGLES study further demonstrated the superior efficacy of varenicline for both psychiatric and non-psychiatric populations and confirmed past findings that there were no significant increase in neuropsychiatric adverse events attributable to varenicline or bupropion relative to nicotine patch or placebo. ${ }^{108,109}$

For persons abusing opioids or taking opioid replacement medications, the interaction between opioids and nicotine may explain the reduced efficacy of NRT for this population. ${ }^{11}$ This is further supported by the finding that the lower the dose of opioid replacement medications taken, the more likely patients are to quit smoking. ${ }^{10}$ Due to mixed findings regarding the efficacy of NRT for patients in opioid dependence treatment, unless contraindicated or unavailable, bupropion which acts on dopaminergic neurons or varenicline which is a partial agonist of the $\alpha 4 \beta 2$ nicotinic acetylcholine receptor will be better first-line options. ${ }^{11,108-110}$ This is particularly the case if providers can address general low adherence to taking medication capsules. ${ }^{111}$ Importantly, clinician training is necessary to ensure that cessation medications are prescribed in combination and at therapeutic dosages meeting individual dependence levels. ${ }^{12}$ This is imperative, as treatment failures often result from under-dosing cessation medications. ${ }^{56}$ Patients should be directed to use combination medications, such as veranicline, bupropion, or long-lasting NRT (e.g., patch) with rescue medication (e.g., NRT gum, or lozenge) to control break-through cravings. ${ }^{113,114}$ 
Currently, there is a great amount of attention to vaping as a potential harm reduction strategy among smokers. ${ }^{115}$ Many smokers are using vaping products as the primary means of quitting or reducing smoking. ${ }^{116}$ While safer than combustible tobacco use, vaping is not necessarily safe. Vaping, as well as smoking, may put individuals at increased risk for respiratory illness and infectious diseases like COVID-19. ${ }^{117}$ The end goal for all patients is abstinence from all nicotine products. Electronic nicotine devices (ENDS) are not FDA-approved smoking cessation aids, and the efficacy of these products for long-term abstinence from conventional cigarettes is uncertain. ${ }^{118}$ ENDS may help some smokers quit; however, the data are mixed, with some studies finding that ENDS users do not completely discontinue combustible tobacco products, resulting in no improvement in health outcomes, ${ }^{116,119,120}$ and others continue ENDS use indefinitely. ${ }^{121}$

Similar to nicotine addiction, MAT is also the most effective treatment option for individuals who abuse opioids. MAT doubles opioid abstinence rates ${ }^{2,122}$ and should be provided 90 days or longer. ${ }^{123}$ All FDA-approved medications for opioid use disorder are clinically effective, with opioid agonists (methadone) or partial agonists (burprenorphine) reducing withdrawal symptoms and the addictive effects of illicit opioids. Methadone is the most commonly used and studied medication. ${ }^{123}$ Some medications have been shown more effective, ${ }^{124,125}$ with buprenorphine shown effective in maintaining treatment engagement and abstinence. ${ }^{126}$ More than half of patients addicted to prescription opioids treated with buprenorphine and naloxone reported they were not misusing opioid prescription drugs 18 months after starting treatment. Buprenorphine has the advantage of flexible administration, either daily, monthly, or every 6 months, but is limited by what type of healthcare providers is able to prescribe buprenorphine and what number of patients they can treat. ${ }^{123}$ Extended-release injectable naltrexone, and opioid antgonist, is also approved for treatment of people with opioid use disorder. Any prescriber can provide naltrexone following a medically managed withdrawal. ${ }^{123}$ There is evidence that naltrexone both reduces cravings from opioids and helps with short-term smoking abstinence, particularly for individuals with depression or alcohol dependence. ${ }^{127-129}$

For both opioid and tobacco use, behavioral treatment components of MAT include motivational interviewing (MI) or motivational enhancement techniques which are effective across substance use disorders. ${ }^{130,131}$ These interventions increase motivation for behavioral change and treatment engagement. During brief MI, non-judgmental, open-ended reflective responses, affirmations and well-timed summaries serve to mirror and reinforce the benefits of behavior change and patients' self-efficacy. ${ }^{132}$ Once in treatment, contingency management (e.g., monetary reinforcement), cognitive behavioral therapy (CBT), and other variants of cognitive and behavioral interventions are proven treatments. ${ }^{56}$ Relapse prevention is also necessary to train individuals to mitigate pain, avoid high-risk situations, and practice replacement coping skills. ${ }^{42,133}$ Behavioral strategies might be employed whether individuals are initially seeking treatment for tobacco use, opioid use, or chronic pain. For example, patient pain motivates a large proportion of physician visits, and such visits could provide a "teachable moment" for addressing smoking and pain medications. ${ }^{134}$ One study found that, when educated about the relationship between pain and tobacco use, patients seeking outpatient pain treatment were over seven times more willing to consider quitting smoking. ${ }^{135}$ It also may be helpful for clinicians to assess the role of anxiety and depression in the intersection of pain, smoking, and opioid use. ${ }^{53}$

\section{Implications for Behavioral Health}

The "quadruple aim" of the healthcare system is to deliver quality, lower cost healthcare to individuals, and improve the work life of healthcare providers resulting in better population health. ${ }^{136,137}$ One of the most expedient means of accomplishing the quadruple aim is to address patients' concurrent smoking and opioid use. Co-treatment models address the fact that polysubstance use is the norm, not the exception. The majority of adults with SUD are interested 
in quitting smoking and motivated to quit at rates consistent with the general population, ${ }^{138}$ but they are not afforded timely, evidence-based treatment options as detailed in the Public Health Service Guidelines. ${ }^{95}$ As a result, patients may overcome their opioid addiction to then die or have severe health issues which are smoking related. ${ }^{138}$ While additional work is needed to better understand how overlapping neural mechanisms contribute to opioid and nicotine addiction, the existing evidence supports co-treatment, buttressed by tobacco-free policies, as a standard of care. ${ }^{2}$ Screening and brief intervention is one of the three top preventive services in terms of cost savings and the potential to improve overall population health. ${ }^{139,140}$ Moreover, promotion of MAT and appropriate referral across addictions (e.g., telephonic services for polysubstance use) hold great promise.

Multilevel changes are needed to foster co-treatment in SUD treatment settings. ${ }^{141}$ At an organizational level, the first goal of co-treatment is the denormalization of tobacco use and other nicotine products by implementing and reinforcing a comprehensive tobacco-free policy. As part of a comprehensive policy, all patients who smoke, vape, or are at risk for relapse to nicotine use should be offered MAT. To do so, agencies must provide the infrastructure for MAT using the standardized 5As model (or SBIRT, STIR variant previously described) with the expectation that clinicians ask, advise, and assess for opioid and nicotine dependence simultaneously. There are proven steps toward taking inpatient, outpatient, and residential treatment settings tobacco free and providing MAT services. One such resource, the DIMENSIONS Tobacco Free Policy Toolkit provides guidance, timelines, and templates for written policy and workflow implementation. ${ }^{142}$

At a provider level, interdisciplinary staff must be trained in evidence-based practices for engaging patients, assessing use, and providing treatments for both opioids and tobacco. A number of evidence-based resources are available from the University of Colorado including tobacco-free treatment toolkits, 5As and MI video training modules, and interdisciplinary workflow models (https://www.bhwellness.org/resources). These resources detail behavioral interventions and pharmacology, including how medication levels may be affected by tobacco use reduction and quit attempts. Providers are further encouraged to take advantage of the resources and model programming continuously updated by the National Behavioral Health Network for Tobacco and Cancer Control (NBHN) (www.bhthechange.org) administered by the National Council. NBHN is one of the eight Centers for Disease Control and Prevention (CDC) national networks created to eliminate tobacco- and cancer-related disparities. The Smoking Cessation Leadership Center is another site with a wealth of archived training opportunities (https:// smokingcessationleadership.ucsf.edu). Several states are building on these training resources to additionally offer opioid treatment program opportunities to participate in a community of practice $(\mathrm{CoP}) .{ }^{143}$ The $\mathrm{CoP}$ is a virtual peer learning environment which fosters discussion of barriers and facilitators to care, as well as specific issues such as MAT, polypharmacy, treatment planning, billing, and health systems change. A current example is the Washington State Department of Health which funds the Tobacco Free Behavioral Health Initiative where Opioid Treatment Network staff are invited to receive Tobacco Treatment Specialist ${ }^{144}$ training and also participate in a CoP. ${ }^{145}$

Simultaneous opioid and tobacco treatment planning is typically appropriate, ${ }^{54}$ and providers will treat tobacco dependence more effectively if it is considered "opt-out" care. ${ }^{146}$ All patients will benefit by brief MI interventions to build motivation for treatment. While studies have demonstrated the feasibility of treating nicotine dependence in patients with SUD, there is still some debate as to whether tobacco and other SUD treatment should be delivered simultaneously or sequentially. ${ }^{147}$ There are valid concerns that fewer patients will engage in delayed treatment, ${ }^{148}$ but opt-out care is best operationalized as a person-centered, strength-based approach aligned with each patient's motivation, readiness, and available resources. ${ }^{123}$ Patients should partner with providers to determine to what degree nicotine and opioid use are simultaneously treated. 
As detailed earlier, standard MAT, including proven FDA medications, should be utilized during co-treatment of opioids and tobacco. Providers should adhere to standards of care for the general population, but be able to tailor the dosage of pharmacotherapy and counseling to SUD patients that will typically have high nicotine dependency levels and complex care needs. Regarding behavioral strategies, education on polysubstance dependence can be provided in a synergistic manner and readiness to quit nicotine use should be routinely reassessed. The majority of issues polysubstance users face are cross-cutting and the proven behavioral therapies previously discussed are appropriate in varied modalities and formats for opioid or nicotine dependence and can be utilized to simultaneously or independently to address polysubstance dependence. ${ }^{58}$ At a minimum, providers can make warm hand-offs to state quitlines at 1-800-QUIT-NOW which are available in every state. Quitlines offer varied combinations of telephonic counseling, pharmacotherapy, and online and texting resources at no cost. ${ }^{149}$ That said, siloed systems and treatment protocols can lead to patient burden, lower quality of care, and non-adherence. ${ }^{150}$ Referrals to quitlines and other community resources are encouraged. At the same time, agencies should provide treatment onsite employing a collaborative care model, team-based care, patient-centered resources, registries, and other sufficient infrastructure. ${ }^{151-153}$

There are limitations to the extant knowledge base. Further work needs to determine if concurrent versus sequential or staged treatment models are most effective, and if this effectiveness differs by type of treatment setting. New technology platforms, accountability mechanisms, payment approaches, and incentive systems for the hardest to reach underserved populations also require testing. ${ }^{150}$ That said, pain clinics, behavioral health treatment settings, methadone, and other opioid treatment programs represent opportunities to also address smoking. Patients with polysubstance use are largely motivated for co-treatment to overcome addictions which are biologically, psychologically, and socially overlapping. With relatively little additional training and favorable attitudes, interdisciplinary healthcare professionals have the ability to concurrently address two deadly epidemics, opioid and nicotine addiction.

\section{Compliance with Ethical Standards}

Conflict of Interest The authors declare that they have no conflict of interest.

\section{References}

1. Hedegaard H, Minino AM, Warner M. Drug overdose deaths in the United States, 1999-2017. NCHS Data Brief, no. 329. Hyattsville, MD: National Center for Health Statistics, 2018.

2. U.S. Department of Health and Human Services, Office of the Surgeon General. Facing addiction in America: the surgeon general's report on alcohol, drugs, and health. Washington, DC: HHS; 2016.

3. Substance Abuse and Mental Health Services Administration. Key substance use and mental health indicators in the United States: results from the 2016 National Survey on Drug Use and Health. HHS Publication No. SMA 17-5044, NSDUH Series H-52. Rockville, MD: Center for Behavioral Health Statistics and Quality, Substance Abuse and Mental Health Services Administration, 2017.

4. McCool RM, Richter KP, Choi WS. Benefits of and barriers to providing smoking treatment in methadone clinics: findings from a national study. American Journal on Addictions 2005;14(4):358-366.

5. U.S. Department of Health and Human Services. The health consequences of smoking: 50 years of progress. A report of the surgeon general. Atlanta, GA: U.S. Department of Health and Human Services, Centers for Disease Control and Prevention, National Center for Chronic Disease Prevention and Health Promotion, Office on Smoking and Health, 2014.

6. Schiller JS, Clarke TC, Norris T. Early release of selected estimates based on data from the January-September 2017 National Health Interview Survey. 2018. https://www.cdc.gov/nchs/data/nhis/earlyrelease/EarlyRelease201803.pdf. Accessed November 18, 2019. 
7. Chisolm MS, Fitzsimons H, Leoutsakos JM, et al. A comparison of cigarette smoking profiles in opioid-dependent pregnant patients receiving methadone or buprenorphine. Nicotine \& Tobacco Research: official journal of the Society for Research on Nicotine and Tobacco. 2013;15(7):1297-1304.

8. Guydish J, Passalacqua E, Tajima B, et al. Smoking prevalence in addiction treatment: a review. Nicotine \& Tobacco Research: official journal of the Society for Research on Nicotine and Tobacco. 2011;13(6):401-411.

9. Haas AL, Sorensen JL, Hall SM, et al. Cigarette smoking in opioid-using patients presenting for hospital-based medical services. American Journal on Addictions. 2008;17(1):65-69.

10. Nahvi S, Richter K, Li X, et al. Cigarette smoking and interest in quitting in methadone maintenance patients. Addictive Behaviors. 2006;31(11):2127-2134.

11. Zirakzadeh A, Shuman C, Stauter E, et al. Cigarette smoking in methadone maintained patients: an up-to-date review. Current Drug Abuse Reviews. 2013;6(1):77-84.

12. Kalman D, Morissette SB, George TP. Co-morbidity of smoking in patients with psychiatric and substance use disorders. American Journal on Addictions. 2005;14(2):106-123.

13. Pajusco B, Chiamulera C, Quaglio G, et al. Tobacco addiction and smoking status in heroin addicts under methadone vs. buprenorphine therapy. International Journal of Environmental Research and Public Health. 2012;9(3):932-942.

14. Kohut SJ. Interactions between nicotine and drugs of abuse: a review of preclinical findings. American Journal of Drug and Alcohol Abuse. 2017;43(2):155-170.

15. Bandiera FC, Anteneh B, Le T, et al. Tobacco-related mortality among persons with mental health and substance abuse problems. PloS One. 2015;10(3):e0120581.

16. Hser YI, McCarthy WJ, Anglin MD. Tobacco use as a distal predictor of mortality among long-term narcotics addicts. Preventive Medicine. 1994;23(1):61-69.

17. Cadet JL, Bisagno V. Neuropsychological consequences of chronic drug use: relevance to treatment approaches. Front Psychiatry. 2015;6:189.

18. Do HP, Nguyen LH, Thi Nguyen NP, et al. Factors associated with nicotine dependence during methadone maintenance treatment: findings from a multisite survey in Vietnam. BMJ Open. 2017;7(7):e015889.

19. Li L, Liu Y, Zhang Y, et al. Temporal changes of smoking status and motivation among Chinese heroin-dependent, methadonemaintained smokers. Addictive Behaviors. 2010;35(10):861-865.

20. Mello NK, Mendelson JH, Sellers ML, et al. Effect of alcohol and marihuana on tobacco smoking. Clinical Pharmacology and Therapeutics. 1980;27(2):202-209.

21. Kapur BM, Hutson JR, Chibber T, et al. Methadone: a review of drug-drug and pathophysiological interactions. Critical Reviews in Clinical Laboratory Sciences. 2011;48(4):171-195.

22. Wahawisan J, Kolluru S, Nguyen T, et al. Methadone toxicity due to smoking cessation - a case report on the drug-drug interaction involving cytochrome P450 isoenzyme 1A2. Annals of Pharmacotherapy. 2011;45(6):e34.

23. Tuesta LM, Fowler CD, Kenny PJ. Recent advances in understanding nicotinic receptor signaling mechanisms that regulate drug selfadministration behavior. Biochemical Pharmacology. 2011;82(8):984-995.

24. Vihavainen T, Relander TR, Leiviska R, et al. Chronic nicotine modifies the effects of morphine on extracellular striatal dopamine and ventral tegmental GABA. Journal of Neurochemistry. 2008;107(3):844-854.

25. Yoon JH, Lane SD, Weaver MF. Opioid analgesics and nicotine: more than blowing smoke. Journal of Pain \& Palliative Care Pharmacotherapy. 2015;29(3):281-289.

26. Hadjiconstantinou M, Neff NH. Nicotine and endogenous opioids: neurochemical and pharmacological evidence. Neuropharmacology. 2011;60(7-8):1209-1220.

27. Spiga R, Martinetti MP, Meisch RA, et al. Methadone and nicotine self-administration in humans: a behavioral economic analysis. Psychopharmacology. 2005;178(2-3):223-231.

28. Elkader AK, Brands B, Selby P, et al. Methadone-nicotine interactions in methadone maintenance treatment patients. Journal of Clinical Psychopharmacology. 2009;29(3):231-238.

29. Richter KP, Hamilton AK, Hall S, et al. Patterns of smoking and methadone dose in drug treatment patients. Experimental and Clinical Psychopharmacology. 2007;15(2):144-153.

30. Michna E, Ross EL, Hynes WL, et al. Predicting aberrant drug behavior in patients treated for chronic pain: Importance of abuse history. Journal of Pain and Symptom Management. 2004;28(3):250-258.

31. Orhurhu VJ, Pittelkow TP, Hooten WM. Prevalence of smoking in adults with chronic pain. Tobacco Induced Diseases. 2015;13(1):17.

32. Galeote L, Kieffer BL, Maldonado R, et al. Mu-opioid receptors are involved in the tolerance to nicotine antinociception. Journal of Neurochemistry. 2006;97(2):416-423.

33. Plesner K, Jensen HI, Hojsted J. Smoking history, nicotine dependence and opioid use in patients with chronic non-malignant pain. Acta Anaesthesiologica Scandinavica. 2016;60(7):988-994.

34. Shi Y, Weingarten TN, Mantilla CB, et al. Smoking and pain: Pathophysiology and clinical implications. Anesthesiology. 2010;113(4):977-992.

35. Drews E, Zimmer A. Modulation of alcohol and nicotine responses through the endogenous opioid system. Progress in Neurobiology. 2010;90(1):1-15.

36. Schmidt BL, Tambeli CH, Gear RW, et al. Nicotine withdrawal hyperalgesia and opioid-mediated analgesia depend on nicotine receptors in nucleus accumbens. Neuroscience. 2001;106(1):129-136.

37. Aamodt AH, Stovner LJ, Hagen K, et al. Headache prevalence related to smoking and alcohol use. The Head-HUNT Study. European Journal of Neurology. 2006;13(11):1233-1238.

38. Amin S, Niu J, Guermazi A, et al. Cigarette smoking and the risk for cartilage loss and knee pain in men with knee osteoarthritis. Annals of the Rheumatic Diseases. 2007;66(1):18-22. 
39. Goesling J, Brummett CM, Meraj TS, et al. Associations between pain, current tobacco smoking, depression, and fibromyalgia status among treatment-seeking chronic pain patients. Pain Medicine. 2015;16(7):1433-1442.

40. Lee SS, Kim SH, Nah SS, et al. Smoking habits influence pain and functional and psychiatric features in fibromyalgia. Joint, Bone, Spine: Revue du Rhumatisme. 2011;78(3):259-265.

41. Saragiotto BT, Kamper SJ, Hodder R, et al. Interventions targeting smoking cessation for patients with chronic pain: an evidence synthesis. Nicotine \& Tobacco Research: official journal of the Society for Research on Nicotine and Tobacco. 2018.

42. Ditre JW, Brandon TH, Zale EL, et al. Pain, nicotine, and smoking: research findings and mechanistic considerations. Psychological Bulletin. 2011;137(6):1065-1093.

43. Hestbaek L, Leboeuf-Yde C, Kyvik KO. Are lifestyle-factors in adolescence predictors for adult low back pain? A cross-sectional and prospective study of young twins BMC Musculoskeletal Disorders. 2006;7:27.

44. Mattila VM, Saarni L, Parkkari J, et al. Predictors of low back pain hospitalization-a prospective follow-up of 57,408 adolescents. Pain. 2008;139(1):209-217.

45. Mikkonen P, Leino-Arjas P, Remes J, et al. Is smoking a risk factor for low back pain in adolescents? A prospective cohort study. Spine. 2008;33(5):527-532.

46. Hooten WM, Vickers KS, Shi Y, et al. Smoking cessation and chronic pain: patient and pain medicine physician attitudes. Pain Practice: the official journal of World Institute of Pain. 2011;11(6):552-563.

47. Hagen KB, Tambs K, Bjerkedal T. A prospective cohort study of risk factors for disability retirement because of back pain in the general working population. Spine. 2002;27(16):1790-1796.

48. Weingarten TN, Podduturu VR, Hooten WM, et al. Impact of tobacco use in patients presenting to a multidisciplinary outpatient treatment program for fibromyalgia. Clinical Journal of Pain. 2009;25(1):39-43.

49. Weingarten TN, Sprung J, Flores A, et al. Opioid requirements after laparoscopic bariatric surgery. Obesity Surgery. 2011;21(9):1407-1412.

50. Qiu YM, Liu YT, Li ST. Tramadol requirements may need to be increased for the perioperative management of pain in smokers. Medical Hypotheses. 2011;77(6):1071-1073.

51. Jin YY, Pollock BG, Coley K, et al. Population pharmacokinetics of perphenazine in schizophrenia patients from CATIE: impact of race and smoking. Journal of Clinical Pharmacology. 2010;50(1):73-80.

52. Hooten WM. Smoking and pain: ask the expert from July/August 2011. Practical Pain Management. 2011;11(6).

53. Zale EL, Maisto SA, Ditre JW. Anxiety and depression in bidirectional relations between pain and smoking: implications for smoking cessation. Behavior Modification. 2016;40(1-2):7-28.

54. Baca CT, Yahne CE. Smoking cessation during substance abuse treatment: what you need to know. Journal of Substance Abuse Treatment. 2009;36(2):205-219.

55. Hill KP, Toto LH, Lukas SE, et al. Cognitive behavioral therapy and the nicotine transdermal patch for dual nicotine and cannabis dependence: a pilot study. American Journal on Addictions. 2013;22(3):233-238.

56. Okoli CTC, Khara M, Procyshyn RM, et al. Smoking cessation interventions among individuals in methadone maintenance: a brief review. Journal of Substance Abuse Treatment. 2010;38(2):191-199.

57. Thurgood SL, McNeill A, Clark-Carter D, et al. A systematic review of smoking cessation interventions for adults in substance abuse treatment or recovery. Nicotine \& Tobacco Research: official journal of the Society for Research on Nicotine and Tobacco. 2016;18(5):993-1001.

58. Prochaska JJ, Delucchi K, Hall SA. A meta-analysis of smoking cessation interventions with individuals in substance abuse treatment or recovery. Journal of Consulting and Clinical Psychology. 2004;72(6):1144-1156.

59. McKelvey K, Thrul J, Ramo D. Impact of quitting smoking and smoking cessation treatment on substance use outcomes: an updated and narrative review. Addictive Behaviors. 2017;65:161-170.

60. Mannelli P, Wu LT, Peindl KS, et al. Smoking and opioid detoxification: behavioral changes and response to treatment. Nicotine \& Tobacco Research: official journal of the Society for Research on Nicotine and Tobacco. 2013;15(10):1705-1713.

61. Clarke JG, Stein MD, McGarry KA, et al. Interest in smoking cessation among injection drug users. American Journal on Addictions. 2001;10(2):159-166.

62. Rohsenow DJ, Monti PM, Colby SM, et al. Naltrexone treatment for alcoholics: effect on cigarette smoking rates. Nicotine \& Tobacco Research: official journal of the Society for Research on Nicotine and Tobacco. 2003;5(2):231-236.

63. Baran-Furga H, Chmielewska K, Bogucka-Bonikowska A, et al. Self-reported effects of methadone on cigarette smoking in methadone-maintained subjects. Substance Use and Misuse. 2005;40(8):1103-1111.

64. Richter KP, Gibson CA, Ahluwalia JS, et al. Tobacco use and quit attempts among methadone maintenance clients. American Journal of Public Health. 2001;91(2):298-266.

65. Stark MJ, Campbell BK. Cigarette smoking and methadone dose levels. American Journal of Drug and Alcohol Abuse. 1993;19(2):209-217.

66. Knudsen HK, Studts JL, Boyd S, et al. Structural and cultural barriers to the adoption of smoking cessation services in addiction treatment organizations. Journal of Addictive Diseases. 2010;29(3):294-305.

67. Weinberger AH, Platt J, Esan H, et al. Cigarette smoking is associated with increased risk of substance use disorder relapse: a nationally representative, prospective longitudinal investigation. Journal of Clinical Psychiatry. 2017;78(2):e152-e160.

68. Knudsen HK, Roman PM. Medicaid, private insurance, and the availability of smoking cessation interventions in substance use disorder treatment. Psychiatric Services. 2015;66(11):1213-1220.

69. Substance Abuse and Mental Health Services Administration, Center for Behavioral Health Statistics and Quality. The N-SSATS Report: Tobacco Cessation Services. Rockville, MD: Substance Abuse and Mental Health Services Administration, 2013.

70. Han B, Hedden SL, Lipari R, et al. Receipt of services for behavioral health problems: results from the 2014 National Survey on Drug Use and Health. NSDUH Data Review. Rockville, MD: Substance Abuse and Mental Health Services Administration, 2015.

71. Friedmann PD, Jiang L, Richter KP. Cigarette smoking cessation services in outpatient substance abuse treatment programs in the United States. Journal of Substance Abuse Treatment. 2008;34(2):165-172. 
72. Schroeder SA, Morris CD. Confronting a neglected epidemic: tobacco cessation for persons with mental illnesses and substance abuse problems. Annual Review of Public Health. 2010;31(1):297-314.

73. Guydish J, Passalacqua E, Tajima B, et al. Staff smoking and other barriers to nicotine dependence intervention in addiction treatment settings: a review. Journal of Psychiatric Drugs. 2007;39(4):423-433.

74. Hunt JJ, Gajewski BJ, Jiang Y, et al. Capacity of US drug treatment facilities to provide evidence-based tobacco treatment. American Journal of Public Health. 2013;103(10):1799-1801.

75. Williams JM, Foulds J, Dwyer M, et al. The integration of tobacco dependence treatment and tobacco-free standards into residential addictions treatment in New Jersey. Journal of Substance Abuse Treatment. 2005;28(4):331-340.

76. Guydish J, Le T, Campbell B, et al. Drug abuse staff and clients smoking together: a shared addiction. Journal of Substance Abuse Treatment. 2017;76:64-68.

77. Pagano A, Tajima B, Guydish J. Barriers and facilitators to tobacco cessation in a nationwide sample of addiction treatment programs. Journal of Substance Abuse Treatment. 2016;67:22-29.

78. Richey R, Garver-Apgar C, Martin L, et al. Tobacco-free policy outcomes for an inpatient substance abuse treatment center. Health Promotion Practice. 2017;18(4):554-560.

79. Hooten WM, Townsend CO, Bruce BK, et al. The effects of smoking status on opioid tapering among patients with chronic pain. Anesthesia and Analgesia. 2009;108(1):308-315.

80. de Dios MA, Vaughan EL, Stanton CA, et al. Adolescent tobacco use and substance abuse treatment outcomes. Journal of Substance Abuse Treatment. 2009;37(1):17-24.

81. Lopez-Quintero C, Hasin DS, de Los Cobos JP, et al. Probability and predictors of remission from life-time nicotine, alcohol, cannabis or cocaine dependence: results from the National Epidemiologic Survey on Alcohol and Related Conditions. Addiction. 2011;106(3):657-669.

82. Morris C, Miller B, Mahalik J. An expanded opportunity to provide tobacco cessation services in primary care. Translational Behavioral Medicine. 2011;1(1):31-34.

83. Brown E, Nonnemaker J, Federman EB, et al. Implementation of a tobacco-free regulation in substance use disorder treatment facilities. Journal of Substance Abuse Treatment. 2012;42(3):319-327.

84. Schroeder SA, Clark B, Cheng C, et al. Helping smokers quit: The Smoking Cessation Leadership Center engages behavioral health by challenging old myths and traditions. Journal of Psychoactive Drugs. 2018;50(2):151-158.

85. Knudsen HK, Muilenburg J, Eby LT. Sustainment of smoking cessation programs in substance use disorder treatment organizations. Nicotine \& Tobacco Research: official journal of the Society for Research on Nicotine and Tobacco. 2013;15(6):1060-1068.

86. Muilenburg JL, Laschober TC, Eby LT. Organizational factors as predictors of tobacco cessation pharmacotherapy adoption in addiction treatment programs. Journal of Addiction Medicine. 2014;8(1):59-65.

87. Krauth D, Apollonio DE. Overview of state policies requiring smoking cessation therapy in psychiatric hospitals and drug abuse treatment centers. Tobacco Induced Diseases. 2015;13:33.

88. Eby LT, Sparks TE, Evans E, et al. A qualitative examination of the positive and negative consequences associated with going tobacco-free in substance abuse treatment: the NY State experience. Nicotine \& Tobacco Research: official journal of the Society for Research on Nicotine and Tobacco. 2012;14(12):1407-1417.

89. Babor TF, McRee BG, Kassebaum PA, et al. Screening, Brief Intervention, and Referral to Treatment (SBIRT): toward a public health approach to the management of substance abuse. Substance Abuse. 2007;28(3):7-30.

90. Bernstein SL, D'Onofrio G. Screening, treatment initiation, and referral for substance use disorders. Addiction Science \& Clinical Practice. 2017;12(1):18.

91. Substance Abuse and Mental Health Services Administration. Screening, Brief Intervention, and Referral to Treatment (SBIRT). Available online at https://www.samhsa.gov/sbirt. 2017. Accessed November 28, 2019.

92. Madras BK, Compton WM, Avula D, et al. Screening, brief interventions, referral to treatment (SBIRT) for illicit drug and alcohol use at multiple healthcare sites: comparison at intake and 6 months later. Drug and Alcohol Dependence. 2009;99(1-3):280-295.

93. Saitz R. Candidate performance measures for screening for, assessing, and treating unhealthy substance use in hospitals: advocacy or evidence-based practice? Annals of Internal Medicine. 2010;153(1):40-43.

94. Bernstein J, Bernstein E, Tassiopoulos K, et al. Brief motivational intervention at a clinic visit reduces cocaine and heroin use. Drug and Alcohol Dependence. 2005;77(1):49-59.

95. Fiore MC, Jaen CR, Baker TB, et al. Treating tobacco use and dependence: 2008 Update. Clinical Practice Guideline. Rockville, MD: U.S. Department of Health and Human Services. Public Health Service, 2008.

96. Land TG, Rigotti NA, Levy DE, et al. The effect of systematic clinical interventions with cigarette smokers on quit status and the rates of smoking-related primary care office visits. PloS One. 2012;7(7):e41649.

97. Moody-Thomas S, Nasuti L, Yi Y, et al. Effect of systems change and use of electronic health records on quit rates among tobacco users in a public hospital system. American Journal of Public Health. 2015;105(Suppl 2):e1-7.

98. Stead LF, Buitrago D, Preciado N, et al. Physician advice for smoking cessation. The Cochrane Database of Systematic Reviews. 2013(5):CD000165.

99. American Academy of Family Physicians. American Academy of Family Physicians Office Champions Tobacco Cessation Federally Qualified Health Centers Project: Final Report. 2014.

100. Longo DR, Stone TT, Phillips RL, et al. Characteristics of smoking cessation guideline use by primary care physicians. Missouri Medicine. 2006;103(2):180-184.

101. Park ER, Gareen IF, Japuntich S, et al. Primary care provider-delivered smoking cessation interventions and smoking cessation among participants in the National Lung Screening Trial. JAMA Internal Medicine. 2015;175(9):1509-1516.

102. ClearWay Minnesota, Minnesota Department of Health, Westat. Tobacco use in Minnesota: 2014 Update. Minneapolis, MN: ClearWay Minnesota and Minnesota Department of Health, 2015.

103. Quinn VP, Stevens VJ, Hollis JF, et al. Tobacco-cessation services and patient satisfaction in nine nonprofit HMOs. American Journal of Preventive Medicine. 2005;29(2):77-84. 
104. Tai B, Hu L, Ghitza UE, et al. Patient registries for substance use disorders. Substance Abuse and Rehabilitation. 2014;5:81-86.

105. Bonhomme J, Shim RS, Gooden R, et al. Opioid addiction and abuse in primary care practice: a comparison of methadone and buprenorphine as treatment options. Journal of the National Medical Association. 2012;104(7-8):342-350.

106. Hartung DM, McCarty D, Fu R, et al. Extended-release naltrexone for alcohol and opioid dependence: a meta-analysis of healthcare utilization studies. Journal of Substance Abuse Treatment. 2014;47(2):113-121.

107. Patnode CD, Henderson JT, Thompson JH, et al. Behavioral counseling and pharmacotherapy interventions for tobacco cessation in adults, including pregnant women: a review of reviews for the U.S. Preventive Services Task Force. Annals of Internal Medicine. 2015;163(8):608-621.

108. Anthenelli RM, Benowitz NL, West R, et al. Neuropsychiatric safety and efficacy of varenicline, bupropion, and nicotine patch in smokers with and without psychiatric disorders (EAGLES): a double-blind, randomised, placebo-controlled clinical trial. Lancet. 2016;387(10037):2507-2520.

109. Nahvi S, Ning Y, Segal KS, et al. Varenicline efficacy and safety among methadone maintained smokers: a randomized placebocontrolled trial. Addiction. 2014;109(9):1554-1563.

110. Hooten WM, Warner DO. Varenicline for opioid withdrawal in patients with chronic pain: a randomized, single-blinded, placebo controlled pilot trial. Addictive Behaviors. 2015;42:69-72.

111. Martin RA, Rohsenow DJ, Tidey JW. Smokers with opioid use disorder may have worse drug use outcomes after varenicline than nicotine replacement. Journal of Substance Abuse Treatment. 2019;104:22-27.

112. Miller ME, Sigmon SC. Are pharmacotherapies ineffective in opioid-dependent smokers? Reflections on the scientific literature and future directions. Nicotine \& Tobacco Research: official journal of the Society for Research on Nicotine and Tobacco. 2015;17(8):955-959.

113. Koegelenberg CF, Noor F, Bateman ED, et al. Efficacy of varenicline combined with nicotine replacement therapy vs varenicline alone for smoking cessation: a randomized clinical trial. JAMA. 2014;312(2):155-161.

114. Steinberg MB, Foulds J, Richardson DL, et al. Pharmacotherapy and smoking cessation at a tobacco dependence clinic. Preventive Medicine. 2006;42(2):114-119.

115. Majeed BA, Weaver SR, Gregory KR, et al. Changing perceptions of harm of e-cigarettes among U.S. adults, 2012-2015. American Journal of Preventive Medicine. 2017;52(3):331-338.

116. Caraballo RS, Shafer PR, Patel D, et al. Quit methods used by US adult cigarette smokers, 2014-2016. Preventing Chronic Disease. 2017; 14:E32.

117. Volkow ND. Collision of the COVID-19 and addiction epidemics. Annals of Internal Medicine. 2020. https://www.acpjournals.org/ doi/10.7326/M20-1212. Accessed May 20, 2020

118. Hartmann-Boyce J, McRobbie H, Bullen C, et al. Electronic cigarettes for smoking cessation. The Cochrane Database of Systematic Reviews. 2016;9:CD010216.

119. Bjartveit K, Tverdal A. Health consequences of smoking 1-4 cigarettes per day. Tobacco Control. 2005;14(5):315-320.

120. Hajek P, Phillips-Waller A, Przulj D, et al. A randomized trial of e-cigarettes versus nicotine-replacement therapy. New England Journal of Medicine. 2019;380(7):629-637.

121. QuickStats: Cigarette smoking status among current adult e-cigarette users, by age group — National Health Interview Survey, United States, 2015. Morbidity and Mortality Weekly Report. 2016;65(42):1177.

122. Connery HS. Medication-assisted treatment of opioid use disorder: review of the evidence and future directions. Harvard Review of Psychiatry. 2015;23(2):63-75.

123. U.S. Department of Health and Human Services, Office of the Surgeon General. Facing Addiction in America: The Surgeon General's Spotlight on Opioids. Washington, DC: HHS; 2018.

124. Lee JD, Nunes EV, Jr., Novo P, et al. Comparative effectiveness of extended-release naltrexone versus buprenorphine-naloxone for opioid relapse prevention (X:BOT): a multicentre, open-label, randomised controlled trial. Lancet. 2018;391(10118):309-318.

125. Larochelle MR, Bernson D, Land T, et al. Medication for opioid use disorder after nonfatal opioid overdose and association with mortality: a cohort study. Annals of Internal Medicine. 2018;169(3):137-145.

126. Mattick RP, Breen C, Kimber J, et al. Buprenorphine maintenance versus placebo or methadone maintenance for opioid dependence. The Cochrane Database of Systematic Reviews. 2014(2):CD002207.

127. Baltieri DA, Daro FR, Ribeiro PL, et al. Effects of topiramate or naltrexone on tobacco use among male alcohol-dependent outpatients. Drug and Alcohol Dependence. 2009;105(1-2):33-41.

128. David SP, Chu IM, Lancaster T, et al. Systematic review and meta-analysis of opioid antagonists for smoking cessation. BMJ Open. 2014;4(3):e004393.

129. King A, Cao D, Vanier C, et al. Naltrexone decreases heavy drinking rates in smoking cessation treatment: an exploratory study. Alcoholism, Clinical and Experimental Research. 2009;33(6):1044-1050.

130. Hettema JE, Hendricks PS. Motivational interviewing for smoking cessation: a meta-analytic review. Journal of Consulting and Clinical Psychology. 2010;78(6):868-884.

131. Heckman CJ, Egleston BL, Hofmann MT. Efficacy of motivational interviewing for smoking cessation: a systematic review and metaanalysis. Tobacco Control. 2010;19(5):410-416.

132. Miller WR, Rollnick S. Motivational interviewing: helping people change. 3rd ed. New York, NY: The Guilford Press; 2013.

133. Burling TA, Burling AS, Latini D. A controlled smoking cessation trial for substance-dependent inpatients. Journal of Consulting and Clinical Psychology. 2001;69(2):295-304.

134. Lawson PJ, Flocke SA. Teachable moments for health behavior change: a concept analysis. Patient Education and Counseling. 2009;76(1):25-30.

135. Hooten WM, LaRowe LR, Zale EL, et al. Effects of a brief pain and smoking cessation intervention in adults with chronic pain: a randomized controlled trialber. Addictive Behaviors. 2019;92:173-179.

136. Berwick DM, Nolan TW, Whittington J. The triple aim: care, health, and cost. Health Affairs. 2008;27(3):759-769. 
137. Bodenheimer T, Sinsky C. From triple to quadruple aim: care of the patient requires care of the provider. Annals of Family Medicine. 2014;12(6):573-576

138. Richter KP, Arnsten JH. A rationale and model for addressing tobacco dependence in substance abuse treatment. Substance Abuse Treatment Prevention and Policy. 2006;1:23.

139. Maciosek MV, LaFrance AB, Dehmer SP, et al. Updated priorities among effective clinical preventive services. Annals of Family Medicine. 2017;15(1):14-22.

140. Maciosek MV, LaFrance AB, Dehmer SP, et al. Health benefits and cost-effectiveness of brief clinician tobacco counseling for youth and adults. Annals of Family Medicine. 2017;15(1):37-47.

141. Ziedonis DM, Guydish J, Williams J, et al. Barriers and solutions to addressing tobacco dependence in addiction treatment programs. Alcohol Res Health. 2006;29(3):228-235.

142. Morris CW, Pavlik J, Mumby SJ, et al. DIMENSIONS: Tobacco-Free Policy Toolkit. 2015. https://www.bhwellness.org/toolkits/ Tobacco-Free-Facilities-Toolkit.pdf. Accessed April 10, 2020.

143. Wenger E, McDermott R, Snyder W. Cultivating communities of practice: a guide to managing knowledge. Cambridge, MA: Harvard Business School Press; 2002.

144. Sheffer CE, Payne T, Ostroff JS, et al. Increasing the quality and availability of evidence-based treatment for tobacco dependence through united certification of Tobacco Treatment Specialists. Journal of Smoking Cessation. 2106;11(4):229-235.

145. Washington State Department of Health. Tobacco-Free Behavioral Health Initiative (TFBHI). Available online at https:// www.doh.wa.gov/ForPublicHealthandHealthcareProviders/HealthcareProfessionsandFacilities/ProfessionalResources/ TobaccoCessationResources/TobaccoFreeBehavioralHealthInitiative. 2020. Accessed April 10, 2020.

146. Richter KP, Ellerbeck EF. It's time to change the default for tobacco treatment. Addiction. 2015;110(3):381-386.

147. Kodl M, Fu SS, Joseph AM. Tobacco cessation treatment for alcohol-dependent smokers: when is the best time? Alcohol Res Health. 2006;29(3):203-207.

148. Joseph AM, Willenbring ML, Nugent SM, et al. A randomized trial of concurrent versus delayed smoking intervention for patients in alcohol dependence treatment. Journal of Studies on Alcohol and Drugs. 2004;65(6):681-691.

149. Stead LF, Perera R, Lancaster T. A systematic review of interventions for smokers who contact quitlines. Tobacco Control. 2007;16 Suppl 1:i3-8.

150. Knickman J, Rama Krishnan KR, Pincus HA, et al. Improving access to effective care for people who have mental health and substance use disorders: a vital direction for health and health care. Discussion Paper. 2016. https://nam.edu/improving-access-toeffective-care-for-people-who-have-mental-health-and-substance-use-disorders-a-vital-direction-for-health-and-health-care/. Accessed May 12, 2020.

151. Watkins KE, Ober AJ, Lamp K, et al. Collaborative care for opioid and alcohol use disorders in primary care: The SUMMIT randomized clinical trial. JAMA Internal Medicine. 2017;177(10):1480-1488.

152. Wagner EH. Chronic disease management: what will it take to improve care for chronic illness? Effective Clinical Practice. $1998 ; 1(1): 2-4$.

153. Unützer J. The Collaborative Care Model: an approach for integrating physical and mental health care in Medicaid Health Homes. 2013. https://www.chcs.org/media/HH_IRC_Collaborative_Care_Model_052113_2.pdf. Accessed May 12, 2020.

Publisher's Note Springer Nature remains neutral with regard to jurisdictional claims in published maps and institutional affiliations. 